\title{
The Glutamatergic Neurotransmission in the Central Nervous System
}

\author{
P. Marmiroli* and G. Cavaletti
}

\section{Department of Neuroscience and Biomedical Technologies, University of Milano-Bicocca, Via Cadore 48, 20900 Monza (MB), Italy}

\begin{abstract}
Glutamate is one of the major neurotrasmitters in mammalian brain and changes in its concentration have been associated with a number of neurological disorders, including neurodegenerative, cerebrovascular diseases and epilepsy. Moreover, recently a possible role for glutamatergic system dysfunction has been suggested also in the peripheral nervous system.

This chapter will revise the current knowledge in the distribution of glutamate and of its receptors and transporters in the central nervous system.
\end{abstract}

Keywords: Central nervous system, excitatory, excitotoxicity, glutamate, peripheral nervous system, receptors, transporters.

\section{THE GLUTAMATERGIC SYSTEM}

The role of glutamatergic neurotransmission into the human brain has been established through a long research history brilliantly reviewed by Watkins and Jane [1] and it represents a fascinating sequence of milestones achieved through different, complementary approaches over more than 70 years. In fact, the presence of high concentrations of glutamate in brain was first recognized in the $1930 \mathrm{~s}$, although its role was at that time considered more in terms of energy metabolism, given the close association of the amino acid with the Krebs cycle. However, the observation that injection of glutamate into brain or carotid arteries produced convulsions suggested a role of glutamate also in electrophysiological processes and led to the speculation that glutamate could be a transmitter in the mammalian central nervous system (CNS). Despite this assumption was poorly supported, this original idea opened up the way for an increasing number of investigations. Actually, the identification of multiple excitatory amino acid receptors preceded the definitive establishment of synaptic function of glutamate. It was in 1968 when McLennan and co-workers [2] compared the effect of a glutamate analogue with glutamate itself and they observed different effects in different thalamic regions, suggesting that more than a single glutamate receptor could exist. A few years later it was demonstrated that large differences in the relative potencies of kainate (a 'glutamate analogue') and N-methyl-d-aspartate (NMDA, an 'aspartate analogue') on the Renshaw cells and different types of spinal interneurons could be evidenced, thus starting an extensive search for multiple glutamate receptors [3].

Since these pioneering studies a huge amount of data have increased our knowledge of the glutamatergic system, although areas of uncertainty are still present. Glutamate (Fig. 1) is the major excitatory amino acid neurotransmitter in the CNS and a possible role has also been recently suggested in the peripheral nervous system, where the current knowledge on the topic is however definitely less complete.

In the human CNS, where glutamatergic transmission can now be directly investigated in vivo using single photon emission computed tomography (SPECT) or proton magnetic resonance spectroscopy, glutamate has been indicated as major player in both neurolasticity and excitotoxicity. In fact, glutamate participates in normal synaptic transmission, as well as in long-term potentiation and long-term depression, i.e. in the basic phenomena involved in learning and memory, and in neuronal maturation and synaptogenesis. By contrast, glutamate excitotoxicity, i.e. the CNS damage induced by excessive glutamatergic signaling, has been linked to chronic neurodegenerative disorders including

*Address correspondence to this author at the Department of Neuroscience and Biomedical Technologies, University of Milano-Bicocca, Via Cadore 48, 20900 Monza (MB), Italy; Tel: +39026448 8116; Fax: +39 026448 8250;

E-mail: paola.marmiroli@unimib.it amyotrophic lateral sclerosis (ALS), multiple sclerosis, Parkinson's disease as well as in ischemia and traumatic brain injury. Moreover, indirect evidence of a possible role of glutamate in peripheral neuropathies of different origin has been recently provided [4-6]. Since glutamate is unable to cross the blood-brain barrier [7], it is established that in order to exert its effects it must be directly produced in the CNS. The synthesis of glutamate is primarily achieved from glucose and $\alpha$-ketoglutarate, with a smaller amount created from glutamine.

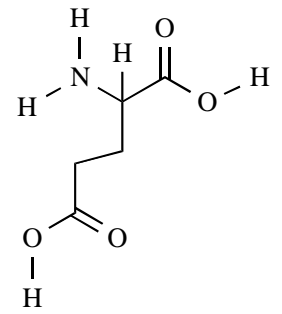

Fig. (1). Chemical structure of glutamate.

\section{VESICLE GLUTAMATE TRANSPORTERS}

Glial cells synthesize glutamine, which is then transported to neurons and converted in glutamate by the activity of glutaminase. Once synthesized, glutamate is stored in neurons into secretory vesicles by the vesicular glutamate transporters (VGLUTs). Once stimulated, these vesicles are able to merge with the cellular membrane thus allowing the neurotransmitter release into the synaptic space. Three subtypes of transporters (VGLUT 1, 2 and 3) have been identified and they share more than 70\% homology [8]. VGLUTs are thought to consist of $8-10$ putative transmembrane domains and they transport glutamate with an affinity that is 100- to 1000 -fold lower than that of the excitatory amino acid transporters (EAATs, see below).

The VGLUT uptake system depends on the proton electrochemical gradient generated by the vesicular proton ATPase. VGLUT activity is also dependent on chloride ion availability; low ion concentrations activate uptake while high concentrations are inhibitory. The VGLUT subtypes are expressed differentially throughout the adult brain. VGLUTs 1 and 2 have a complementary distribution and are expressed in the terminals of all glutamatergic synapses. VGLUT1 is more abundant in cerebral cortex, cerebellar cortex and hippocampus, while VGLUT2 is predominant in diencephalon and rhombencephalon $[9,10]$. VGLUT3 is expressed in the striatum, hippocampus and cortex and it has an axonal as well as somatic and dendritic subcellular distribution [8].

Besides VGLUT, sialin, a highly expressed vesicular transporter classically considered to be involved in aspartate storage, has also been demonstrated to be able to transport glutamate [11]. 


\section{GLUTAMATE RECEPTORS}

Glutamatergic neurotransmission occurs through specific receptors, subdivided into two classes: ionotropic receptors, which act as ion channels, and metabotropic receptors, which are linked to intracellular second messenger systems [12].

\section{Ionotropic Glutamate Receptors}

Ionotropic glutamate receptors are further subdivided in three subclasses on the basis of their pharmacologic affinities to synthetic ligands: the NMDA receptors (NMDAR), the a-amino-3-hydroxy5-methylisoxazole- 4-propionic acid receptors (AMPAR), and the kainate receptors (KR) (Fig. 2).

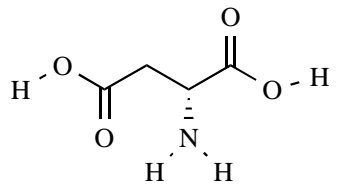

(a)

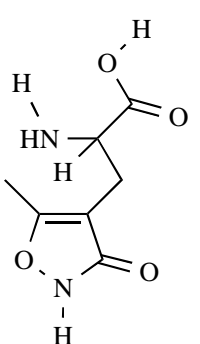

(b)

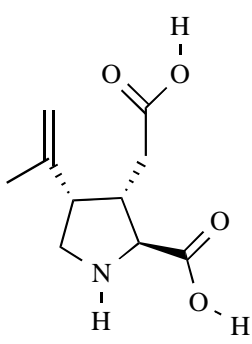

(c)
Fig. (2). Chemical structures of NMDA (a), AMPA (b) and kainate (c).

All these receptors are composed of four subunits and variation in their expression may induce different response properties. It has been estimated that approximately $70 \%$ of the synapses in the mammalian brain contain NMDAR or AMPAR [13], with a higher density in the cerebral cortex, hippocampus, amygdala, striatum and septum.

The NMDAR is the glutamate receptor most extensively studied so far. Calcium influx through NMDAR ion channels activates intracellular kinases and phosphatases, thereby altering the characteristics of the synapse and giving the basis for neuronal transmission. The NMDAR channel is a heterotetramer generally composed of two NR1 subunits and two NR2 subunits (although it can be composed by combination of three possible subunits, NR13) [14]. When activated, the NMDAR allows the influx of different cations, but the ion relevant to CNS physiology and pathology is calcium. The NMDAR exhibits a complex gating mechanism, requiring not only glutamate binding, but also cofactors binding and cellular depolarization. Among the binding cofactors, an important role is played by glycine [15] and, possibly, by polyamines (e.g spermine) either directly [16] or through a glycine-mediated effect [17]. Regarding the role of membrane depolarization, Mayer et al. [18] showed that depolarization of the NMDAR-expressing neuron is necessary to allow electrostatical removal of a magnesium ion normally blocking current entry at the level of the NMDAR channel pore. At least under physiological conditions, magnesium is removed by the activation of AMPAR and KR or by back propagating action potentials [19-21]. While the NR1 subunits form the ion channel proper, NR2 subunits have more of a regulatory role in NMDAR function and their subtypes are differentially expressed in the various CNS areas: NR2A are widely distributed in the brain, while NR2B are expressed primarily in the forebrain, $\mathrm{NR} 2 \mathrm{C}$ in the cerebellum and NR2D in the thalamus [22]. Besides their role in the regulation of the NMDAR activity, it has been suggested that NR2 may contribute to the formation of specialized postsynaptic microenvironments through link to postsynaptic proteins [23]. The NR3 subunit has also been identified: the NR3A isoform is widely expressed in the CNS, while the NR3B isoform is expressed primarily in motor neurons [24]. Their role and activity in the glutamatergic signaling is still unclear.
AMPAR have a lower affinity for glutamate than NMDAR and they are weakly permeable to external calcium ions [25-28]. They are responsible for an initial excitatory potential when the neurotransmitter is present in the synapse. As previously mentioned, this change in membrane polarization is crucial to NMDAR activity, since it allows the removal of a magnesium ion from the channel in the NMDAR thus making calcium transit through the channel possible. The AMPAR (as well as the KR) belong to the same superfamily as the NMDAR and they share approximately $25 \%$ homology. AMPAR are composed of a combination of four subunits (GluR1-4). Contrary to the NMDAR, they require only glutamate binding for activation. The specificity of cation influx of AMPAR depends on their subunit composition. In fact, while GluR1, GluR3 and GluR4 display inwardly rectifying current-voltage and calcium permeability, the GluR2 subunit removes calcium permeability $[27,29,30]$. The demonstration that AMPAR-negative NMDAR-positive synapses occur in the CNS was achieved [31, 32], and it was also demonstrated that their proportion tend to decrease during CNS development and maturation [33, 34].

Although their knowledge is more limited in comparison to the results achieved in the characterization, localization and understanding of the role of NMDAR and AMPAR, the most recent studies agree that the properties of KR are similar to AMPAR and that they also allow ion flux simply through a mechanism mediated by glutamate binding. Contrarily to AMPAR, that are localized mostly in the postsynaptic membrane, it has been shown that KR may be localized also pre-synaptically $[35,36]$, where they reduce the magnesium block in NMDAR. KR are composed of subunits from GluR5-7 (also known as GluK5-7) and KA1-2 (also known as GluK1-2). The number of synapses carrying KR is remarkably low if compared with those expressing NMDAR and AMPAR in the CNS, although they can be detected ubiquitously [37-39].

A fourth orphan family of delta receptors (GluR $\delta 1$ and GluR $\delta 2)$ have also been described, although their role is unclear [40]. GluR $\delta 1$ and GluR $\delta 2$ share $56 \%$ amino acid identity but only 17 to $28 \%$ identity with other ionotropic glutamate receptors and they are not activated by AMPA, kainate, NMDA or glutamate when expressed alone or in combination with other subunits in heterologous expression systems [41]. They have been identified only in Purkinje cells of the cerebellum and they seem to act as an AMPA-like receptor.

\section{Metabotropic Receptors}

Metabotropic glutamate receptors (mGluR) are structurally different from ionotropic NMDAR, AMPAR and KR, consisting of a single polypeptide with seven transmembrane domains [42]. Eight mGluR have been identified so far and they have been classified in three groups (groups I, II and III, respectively, Table 1) based on the intracellular cascades that they are coupled with, sequence homology and pharmacology.

It was previously assumed that all the mGluR use G-proteins as a transduction molecule, but recent studies evidenced that also Gprotein-independent signaling can occur [43]. Group I mGluR include mGluR1 and mGluR5 and their activation is linked through G-proteins to the activation of phospholipase $\mathrm{C}$ and subsequent inositol triphosphate production and intracellular calcium mobilization [44, 45]. Immunoreactivity for mGlu1 has been extensively found in the CNS, being most intense in Purkinje cells of the cerebellar cortex and in the olfactory bulb, but present also in the neurons of the lateral septum, globus pallidus, most of the thalamic nuclei, substantia nigra and dorsal cochlear nucleus, generally at the postsynaptic level. mGlu 5 is expressed mainly in telencephalic regions, including the cerebral cortex, olfactory bulbs, striatum, nucleus accumbens, lateral septal nucleus and dendritic fields of pyramidal and granule cells of the hippocampus, but also 
Table 1. Summary of the Key Features of Metabotropic Glutamate Receptors

\begin{tabular}{|l|l|l|}
\hline Group & Receptor & Cells expression \\
\hline \hline Group I & mGluR1 & Neurons, predominantly postsynaptic \\
\hline & mGluR5 & $\begin{array}{l}\text { Neurons, predominantly postsynaptic } \\
\text { Astrocytes }\end{array}$ \\
\hline Group II & mGluR2 & Neurons, presynaptic and postsynaptic \\
\hline Group III & mGluR3 & $\begin{array}{l}\text { Neurons, presynaptic and postsynaptic } \\
\text { Astrocytes }\end{array}$ \\
\hline & mGluR4 & Neurons, predominantly presynaptic \\
\hline & mGluR6 & Bipolar cells in the retina, postsynaptic \\
\hline & mGluR7 & Neurons, presynaptic \\
\hline & mGluR8 & Neurons, predominantly presynaptic \\
\hline
\end{tabular}

in the cerebellum and brainstem regions as well as in spinal cord ventral horn [46]. In a few studies, mGlu5 immunoreactivity has been reported not only in somatodendritic domains of neurons, but also in axons [47] and in astrocytes [48]. Group I mGluR also modulates excitatory postsynaptic potentials via a different mechanism involving tyrosine kinases in a G-protein-independent fashion in hippocampal synapses [43]. mGluR2 and mGluR3 belong to the Group II and their activation determines a decrease in adenylcyclase signaling, leading to downstream inhibition of voltage-dependent calcium channels $[49,50]$. The distribution of mGlu2 is more limited in the CNS than that of mGlu1 and mGlu5 and it is mainly restricted to the Golgi cells in the cerebellar cortex, mitral cells of the accessory olfactory bulb, external part of the anterior olfactory nucleus and some neurons in the entorhinal and parasubicular cortices, although less intense expression has been described in other brain areas not only in the somato-dendritic domains, but also in axons [46]. By contrast mGlu3 is expressed extensively throughout not only in postsynaptic elements, but also in presynaptic elements and glial processes in the cerebral cortex, hippocampus and striatum [51]. Since presynaptic calcium is critical for effective neurotransmission, group II mGluR modulate it via their action on voltage-gated calcium channels. Group III mGluR include four glutamate receptors (mGluR4, mGluR6, mGluR7 and mGluR8) with properties and effects similar to those described for the group II mGluR [50]. mGlu7 is the most extensively distributed among these group III receptors, located in the presynaptic active zone in axon terminals of CNS neurons, while mGlu6 is mainly restricted to the postsynaptic dendritic part of rod bipolar cells in the retina and mGlu4 to the presynaptic active zone of cerebellar granule cells, olfactory bulb, entorhinal cortex, hippocampus, striatum, and brainstem neurons [46]. Also the expression pattern of mGlu8 is more restricted than that of mGlu7 with a demonstrated expression at the presynaptic level in the olfactory bulbs, piriform cortex, entorhinal cortex, and brainstem. Strong expression for mGlu 8 has also been noted in a few cells in the deeper layers of the cerebral cortex [46].

\section{EXCITATORY AMINO ACID TRANSPORTERS}

In the instance of the glutamatergic transmission, transport systems is particularly relevant to regulate neurotransmission because glutamate is not metabolized by an extracellular enzyme. In fact, since glutamate is not subsequently degraded, glutamatergic activity if finely regulated through the removal of glutamate from the synapse by EAATs. Through their activity, a small amount of glutamate undergo presynaptic neurons re-uptake, while most is collected into astrocytes [52]. Several membrane transporters have been identified that are capable of regulating the cellular influx/efflux of glutamate, but it is accepted that the majority of its transport in the CNS, particularly as related to excitatory transmission, is mediated by high-affinity, sodium-dependent, EAATs expressed by neurons and glial cells. The majority of synapses in the CNS are in close apposition with glia, and glial EAATs are responsible for the most of glutamate uptake [53, 54], while neuronal EAATs appear to have more specialized roles [55]. Early indications that glutamate uptake in the CNS was not mediated by a single homogenous system were provided by comparative pharmacological studies [56] and in early 90s three different EAATs were identified in different rodents organs: GLAST [57], GLT-1 [58] and EAAC1 [59]. Just 2 years later the isolation of the homologous transporters from human brain, which were referred to as EAAT1, 2 and 3, respectively was reported [60] and subsequently EAAT4 and EAAT5 were isolated from the retina $[61,62]$. Sequence comparisons among the 5 EAATs indicate that there is about 50-60\% homology among the EAATs subtypes [63]. Despite some inconsistency in the reported results, the localization and the distribution within the CNS of the EAATs is sufficiently characterized. EAAT3 and EAAT4 are considered to be neuronal transporters [64], although they are differently distributed in the brain. EAAT3 is more abundant throughout the forebrain and spinal cord, with the highest expression detectable in the hippocampus, basal ganglia, and cortical structures, while EAAT4, on the other hand, is mainly expressed in the cerebellum Purkinje neurons. EAAT1 and EAAT2 are considered to be glial transporters, and also in this case their relative distribution in the brain is different, with EAAT1 being predominantly restricted to the cerebellum and EAAT2 abundant throughout the CNS. While all the other EAATs are rather widely distributed in the adult brain, EAAT5 expression seems to be limited to the retina, where it is found in neurons and in Muller cells [65].

\section{GLUTAMATE AND GLIAL CELLS}

Although for several years the study of the role and function of glutamate and its receptor and active transport system have been focused on neuronal glutamatergic transmission under physiologic and pathologic conditions in the CNS, evidence is rapidly increasing to support the fact that the knowledge of the bidirectional neuronal-glial cells cross-talk should be enhanced (Fig. 3).

The issue of astrocytic exocitotic release of neurotransmitters is still raising considerable controversy among neuroscientists [66, 67], since major questions are only partly answered regarding the capacity of astrocytes to store and release neurotransmitters ("gliotransmitters") as well as the possible release mechanism. Although the criteria for a substance released from neurons to be classified as a neurotransmitter have been defined since the early 70s (although subsequently amended and modified) [68, 69], similar criteria allowing to characterize a substance such as glutamate as a gliotransmitter have been identified and formalized 


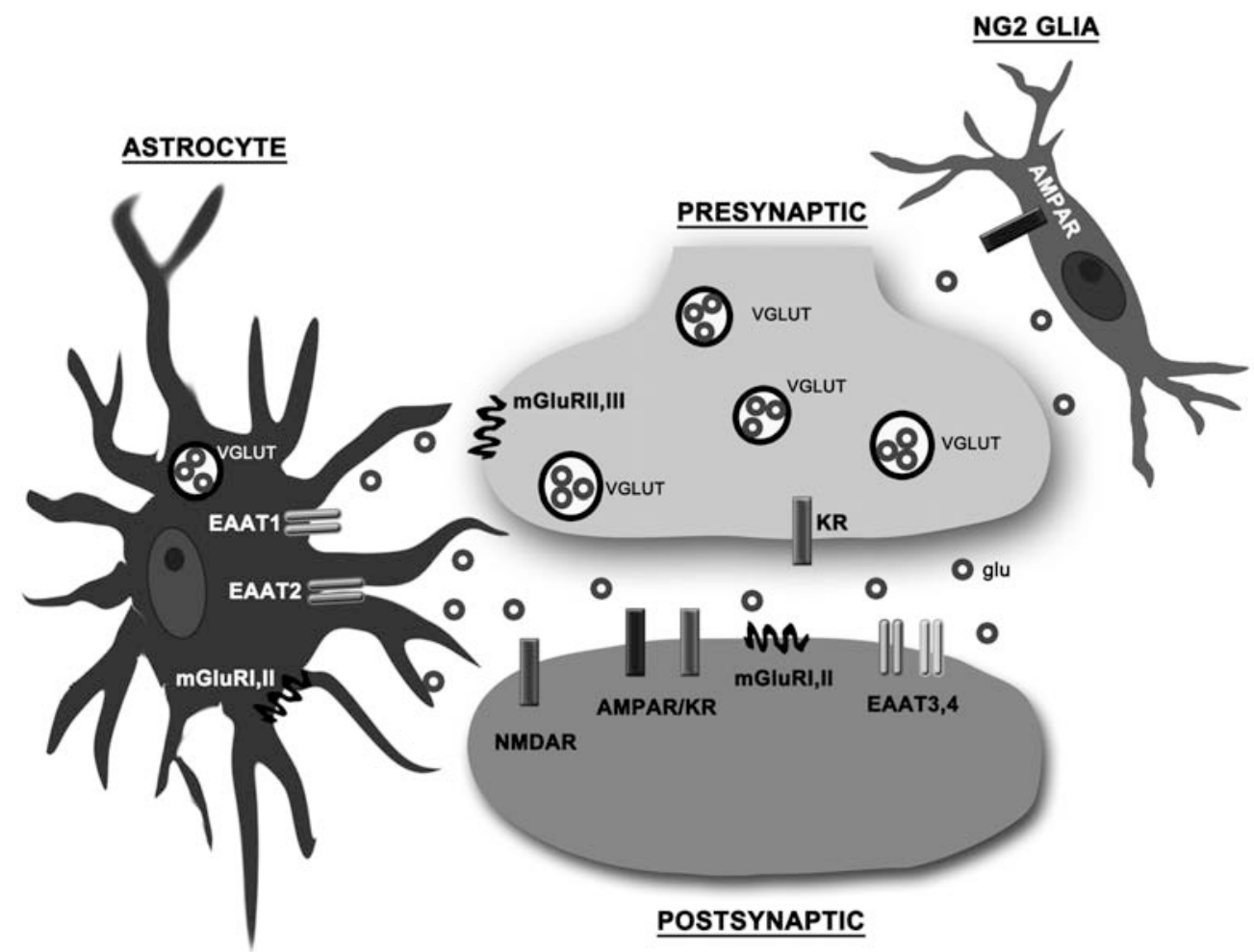

Fig. (3). Summary of the most precisely characterized localizations of glutamate transporters and receptors in neurons and glial cells.

VGLUT $=$ vesicular glutamate transporters,NAAG $=\mathrm{N}$-acetylaspartylglutamate, GCPII $=$ Glutamate carboxypeptidase II, NMDAR $=$ NMDA receptor, AMPAR $=$ AMPA receptor, $\mathrm{KR}=$ kainate receptor, mGluRI-III $=$ metabotropic glutamate receptors, groups I-III, EAAT1-4 $=$ excitatory amino acid transporters 1-4.

only more recently [70-72]. According to these criteria a chemical can be defined as a gliotransmitter if (i) it is synthetized by and/or stored in glial cells, (ii) it has a regulated release triggered by physiological and/or pathological stimuli, (iii) it is able to activate rapid (milliseconds to seconds) responses in neighboring cells; and (iv) it has an established role in pathological and/or physiological processes. It is now strongly suggested that astrocytes (as well as other glial cells) can release gliotransmitters into the extracellular space using several different mechanisms, including channels [7375], transporters [76, 77] or calcium-dependent exocytosis [78].

The intracellular synthetic machinery required for glutamate production has been demonstrated and characterized in astrocytes, which possess the enzyme pyruvate carboxylase and therefore can synthesize glutamate de novo [79] starting from $\alpha$-ketoglutarate, usually via transamination of another amino acid, such as aspartate [80]. The first evidence for calcium-dependent glutamate release from astrocytes was achieved more than 25 years ago in in vitro systems [78] and subsequently confirmed in different experimental paradigms using chemical as well as physical stimulations [81-84].

The majority of intracellular calcium necessary for astrocytes to release glutamate originates from endoplasmic reticulum, although mitochondria can modulate intracellular calcium and affect exocytosis [85]. Once synthetized and properly stored, calciumdependent release of transmitters depends on the presence of exocytotic secretory machinery, and to this aim astrocytes express the proteins of the soluble $\mathrm{N}$-ethyl maleimidesensitive fusion protein attachment protein receptor (SNARE) complex: syntaxin 1, synaptosome-associated protein of $23 \mathrm{kDa}$ (SNAP-23), synaptobrevin 2 ( $\mathrm{Sb} 2$, also known as vesicle-associated membrane protein 2, VAMP 2) as well as several ancillary proteins to this complex, including synaptotagmin 4 [86]. Proteins utilized for sequestering glutamate into intracytoplasmatic vesicles also have been demonstrated in astrocytes (e.g. the vacuolar type of proton ATPase, V-ATPase) [87]. V-ATPase is critical in the process of glutamate storage into vescicles, since all the three known isoforms of VGLUTs in astrocytes require its activity for their functioning [88-91]. VGLUTs activity is differential in astrocytes, as demonstrated by selective over-expression studies showing that VGLUT3, but not VGLUT1 or VGLUT2, enhances mechanically induced calcium-dependent glutamate release.

Secretory vesicles in astocytes, which are essential morphological elements to demonstrate regulated calciumdependent exocytosis, have been demonstrated by electron microscope immuno-localization studies [92] and they appear as electron lucent vesicles with a diameter in the range 30-100 nm [89, 90]. Electron lucent vesicles with a size of approximately $50 \mathrm{~nm}$ have been interpreted as recycling glutamatergic vesicles which capture the extracellular substance after its release [93]. Much larger vesicles, over $1 \mu \mathrm{m}$ in diameter, form within minutes of repeated stimulation with pharmacological dosages $(5-50 \mathrm{mM})$ of glutamate [94, 95], but it is still unclear if they are relevant to physiological conditions or if they are a sort of "experimental artifact". Intracellular trafficking of glutamatergic vesicles in astrocytes was also demonstrated [93], as well as their fusion to the plasma membrane [90].

Besides the possibility of astrocytes releasing glutamate and influencing neuronal activity, the backward pathway has also been investigated and show that many glial cells have the capacity to respond rapidly to neuronal activity. This peculiar aspect has been studied in relationship with glutamatergic transmission particularly in a distinct class of glial cells, known as NG2 cells representing up to $5-10 \%$ of the glial population [96] and present in both the grey and white matter of the SNC, which express ionotropic receptors 
for glutamate and GABA. In fact, it has been demonstrated that NG2 cells form direct synaptic junctions with axons, which enable transient activation of these receptors. Most of the data available so far rely on neurophysiological assays, demonstrating that these neuron-glia synapses exhibit all the hallmarks of "typical" neuronneuron synapses, i.e. very rapid activation, facilitation and depression, quantized responses, and presynaptic inhibition. It was in 2000 when Bergles and co-workers demonstrated for the first time the existence of functional neuron-glia synapses in the brain [97]. However, the real nature of the cells studied by Bergles and co-workers is still not clearly established, since they considered these postsynaptic glial cells expressing AMPAR as oligodendrocyte precursor cells, while other researchers demonstrated that not all NG2 cells develop into oligodendrocytes but can also generate protoplasmic astrocytes and even neurons [96, 98, 99]. However, at the moment the most accepted interpretation is that NG2 cells represent an individual class of glial cells in the adult CNS [100, 101].

The functional role of ionotropic receptors on glial cells is still not completely elucidated and the original interpretation is that they are functional to the detection of increased local transmitter levels, either in physiologic (e.g. spillover of transmitter from neuronal synapses) or pathological conditions. Experimental evidence is still rather inconclusive, and the results obtained in astrocytes closely surrounding synapses [102, 103] and in NG2 cells [104, 105] are not easy to be combined in a unifying theory. Moreover, neurophysiological recordings of NG2 cells derived from the hippocampus of experimental animals revealed that AMPAR are subject to transient activation after glutamate stimulation [97, 106, 107] with a receptor-mediated current duration comparable to those produced at neuronal synapses through vesicular fusion. Similar results were obtained also in other areas of the CNS, including cerebellum [108, 109], cortex [110], brainstem [111] and corpus callosum $[112,113]$. The hypothesis that these events were very close to that attributed to synaptic activity was further supported by several experimental data, since they occur with minimal delay after axonal action potentials, they can be evoked by a single action potential and prevented by the synaptic blocker tetrodotoxin [114]. A more recent study also demonstrated that AMPAR-induced currents can be evoked and maintained with repetitive stimulation [113], indicating that terminals possess all the machinery necessary to release, recycle and refill vesicles with glutamate. It is now increasingly accepted that synaptic-like signaling is a property of at least some classes of glial cells and that this form of rapid neuronglia communication is widespread in the brain.

Despite the neurophysiological demonstration of the presence of this synaptic-like communication between neurons and glial cells, anatomical studies have not consistently described their features in the mature CNS. It is possible that one of the main reasons for this discrepancy relies on the difficulty in the clear identification of NG2 cells and of their tiny processes in ultrastructural studies [101, 115]. Despite this limitation, ultrastructural evidence of junctions between axons and NG2 cell membranes that exhibit many features of traditional synapses (e.g. alignment and spacing of axonal and NG2 cell membranes over a restricted area, presence of small clear vesicles and mitochondria in the axon near the junction) have been provided [97, 108, 113] and confocal microscopic analysis has shown the accumulation of VGLUT1 adjacent to the processes of NG2 cells in the corpus callosum [113]. The few experimental results available so far suggest that AMPAR receptors are clustered along NG2 cells processes [116].

\section{CONCLUSIONS}

Glutamate is the principal excitatory neurotransmitter in the brain. Knowledge of the glutamatergic synapse features has advanced enormously over the last 10-20 years, primarily based on the use of morphological, electrophysiological, pharmacological and molecular biology techniques to study glutamatergic neurons/glia distribution, glutamate receptors and transporters localization and function not only in the central, but also in the
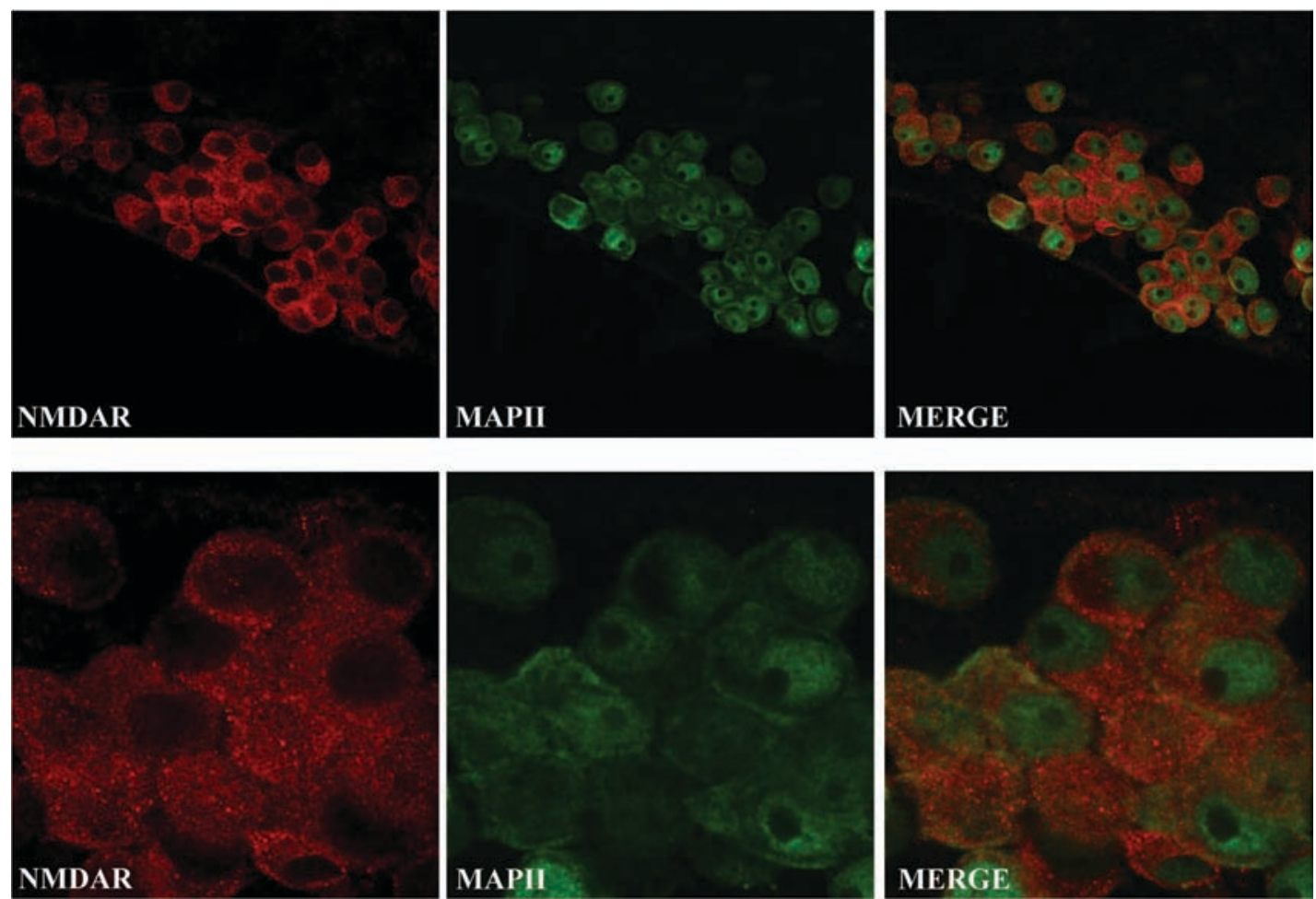

Fig. (4). Embryonic rat dorsal root ganglia neurons stained with an anti-NMDAR antibody (left) and with a neuronal specific marker (MAPII, center) resulting in the merge image indicating a colocalization of the staining in neuronal cytoplasm. 
peripheral nervous system (Fig. 4). Nevertheless, several aspects still need to be elucidated to fully understand if and how the glutamatergic system can be effectively targeted to treat a wide spectrum of human diseases.

\section{REFERENCES}

[1] Watkins, J.C.; Jane, D.E. The glutamate story. Br. J. Pharmacol. 2006, 147 Suppl 1:S100-8.

[2] McLennan, H.; Huffman, R.D.; Marshall, K.C..Patterns of excitation of thalamic neurones by amino-acids and by acetylcholine. Nature 1968,219, 387-8.

[3] McCulloch, R.M.; Johnston, G.A.; Game, C.J.; Curtis, D.R. The differential sensitivity of spinal interneurones and Renshaw cells to Kainate and Nmethyl-D-aspartate. Exp Brain Res 1974,21:515-8.

[4] Boyle, F.M.; Wheeler, H.R.; Shenfield, G.M.. Glutamate ameliorates experimental vincristine neuropathy. J. Pharmacol. Exp. Ther. 1996,279, $410-5$.

[5] Carozzi, V.A.; Chiorazzi, A.; Canta, A.; Lapidus, R.G.; Slusher, B.S.; Wozniak, K.M.; Cavaletti, G. Glutamate Carboxypeptidase Inhibition Reduces the Severity of Chemotherapy-Induced Peripheral Neurotoxicity in Rat. Neurotox. Res. 2010, 17, 380-91

[6] Zhang, W.; Slusher, B.; Murakawa, Y.; Wozniak, K.M.; Tsukamoto, T.; Jackson, P.F.; Sima, A.A. GCPII (NAALADase) inhibition prevents longterm diabetic neuropathy in type 1 diabetic BB/Wor rats. J.Neurol.Sci .2002,194, 21-8.

[7] Hediger, M.A.; Welbourn, T.C. Introduction: glutamate transport, metabolism, and physiological responses. Am. J. Physiol. 1999,277, F477-80.

[8] Shigeri, Y.; Seal, R.P.; Shimamoto, K. Molecular pharmacology of glutamate transporters, EAATs and VGLUTs. Brain. Res. Brain. Res. Rev. 2004,45, 250-65.

[9] Fremeau, R.T. Jr., Troyer, M.D.; Pahner, I.; Nygaard, G.O.; Tran, C.H.; Reimer, R.J.; Bellocchio, E.E.; Fortin, D.; Storm-Mathisen, J.; Edwards, R.H. The expression of vesicular glutamate transporters defines two classes of excitatory synapse. Neuron 2001,31, 247-60.

[10] Kaneko, T.; Fujiyama, F.; Hioki, H. Immunohistochemical localization of candidates for vesicular glutamate transporters in the rat brain. J. Comp. Neurol . 2002,444, 39-62.

[11] Miyaji, T.; Echigo, N.; Hiasa, M.; Senoh, S.; Omote, H.; Moriyama, Y. Identification of a vesicular aspartate transporter. Proc. Natl. Acad. Sci. U S A 2008,105, 11720-4.

[12] Schoepfer, R.; Monyer, H.; Sommer, B.; Wisden, W.; Sprengel, R.; Kuner, T.; Lomeli, H.; Herb, A.; Kohler, M.; Burnashev, N.; et al. Molecular biology of glutamate receptors. Prog. Neurobiol. 1994,42, 353-7.

[13] Bekkers, J.M.; Stevens, C.F. NMDA and non-NMDA receptors are colocalized at individual excitatory synapses in cultured rat hippocampus. Nature 1989,341, 230-3.

[14] Lau, A.; Tymianski, M. Glutamate receptors, neurotoxicity and neurodegeneration. Pflugers Arch. 2010,460, 525-42.

[15] Johnson, J.W.; Ascher, P. Glycine potentiates the NMDA response in cultured mouse brain neurons. Nature 1987,325, 529-31.

[16] Rock, D.M.; MacDonald, R.L. Spermine and related polyamines produce a voltage-dependent reduction of N-methyl-D-aspartate receptor singlechannel conductance. Mol. Pharmacol. 1992,42, 157-64.

[17] Benveniste, M.; Mayer, M.L. Multiple effects of spermine on N-methyl-Daspartic acid receptor responses of rat cultured hippocampal neurones. $J$. Physiol. 1993,464, 131-63.

[18] Mayer, M.L.; Westbrook, G.L.; Guthrie, P.B. Voltage-dependent block by $\mathrm{Mg} 2+$ of NMDA responses in spinal cord neurones. Nature 1984,309, 261-3.

[19] Markram, H.; Lubke, J.; Frotscher, M.; Sakmann, B. Regulation of synaptic efficacy by coincidence of postsynaptic APs and EPSPs. Science 1997,275, 213-5.

[20] Stuart, G., Spruston, N.; Sakmann, B.; Hausser, M. Action potential initiation and backpropagation in neurons of the mammalian CNS. Trends Neurosci. 1997,20, 125-31.

[21] Kampa, B.M.; Clements, J.; Jonas, P.; Stuart, G.J. Kinetics of Mg2+ unblock of NMDA receptors: implications for spike-timing dependent synaptic plasticity. J. Physiol. 2004,556, 337-45.

[22] Buller, A.L.; Larson, H.C.; Schneider, B.E.; Beaton, J.A.; Morrisett, R.A.; Monaghan, D.T. The molecular basis of NMDA receptor subtypes: native receptor diversity is predicted by subunit composition. J. Neurosci. 1994,14, 5471-84.

[23] Sattler, R.; Xiong, Z.; Lu, W.Y.; Hafner, M.; MacDonald, J.F.; Tymianski, M. Specific coupling of NMDA receptor activation to nitric oxide neurotoxicity by PSD-95 protein. Science 1999,284, 1845-8.

[24] Chatterton, J.E.; Awobuluyi, M.; Premkumar, L.S.; Takahashi, H.; Talantova, M.; Shin, Y.; Cui, J.; Tu, S.; Sevarino, K.A.; Nakanishi, N.; Tong, G.; Lipton, S.A.; Zhang, D. Excitatory glycine receptors containing the NR3 family of NMDA receptor subunits. Nature 2002,415, 793-8.
[25] Lambolez, B.; Audinat, E.; Bochet, P.; Crepel, F.; Rossier, J. AMPA receptor subunits expressed by single Purkinje cells. Neuron 1992,9, 247-58.

[26] Jonas, P.; Racca, C.; Sakmann, B.; Seeburg, P.H.; Monyer, H. Differences in $\mathrm{Ca} 2+$ permeability of AMPA-type glutamate receptor channels in neocortical neurons caused by differential GluR-B subunit expression. Neuron 1994,12, 1281-9.

[27] Geiger, J.R.; Melcher, T.; Koh, D.S.; Sakmann, B.; Seeburg, P.H.; Jonas, P.; Monyer, H. Relative abundance of subunit mRNAs determines gating and $\mathrm{Ca} 2+$ permeability of AMPA receptors in principal neurons and interneurons in rat CNS. Neuron 1995,15, 193-204.

[28] Tempia, F.; Kano, M.; Schneggenburger, R.; Schirra, C.; Garaschuk, O.; Plant, T.; Konnerth, A. Fractional calcium current through neuronal AMPAreceptor channels with a low calcium permeability. J. Neurosci. 1996,16, 456-66.

[29] Burnashev, N.; Zhou, Z.; Neher, E.; Sakmann, B. Fractional calcium currents through recombinant GluR channels of the NMDA, AMPA and kainate

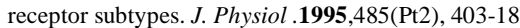

[30] Hollmann, M.; Hartley, M.; Heinemann, S. Ca2+ permeability of KAAMPA--gated glutamate receptor channels depends on subunit composition. Science 1991,252, 851-3.

[31] Liao, D.; Hessler, N.A.; Malinow, R. Activation of postsynaptically silent synapses during pairing-induced LTP in CA1 region of hippocampal slice. Nature 1995,375, 400-4.

[32] Malenka,R.C.; Nicoll, R.A. Silent synapses speak up. Neuron 1997,19, 473-

[33] Wu, G.; Malinow, R.; Cline, H.T. Maturation of a central glutamatergic synapse. Science 1996,274, 972-6.

[34] Petralia, R.S.; Wang, Y.X.; Wenthold, R.J. Histological and ultrastructural localization of the kainate receptor subunits, KA2 and GluR6/7, in the rat nervous system using selective antipeptide antibodies. J. Comp. Neurol. 1994,349, 85-110.

[35] Castillo, P.E.; Malenka, R.C.; Nicoll, R.A. Kainate receptors mediate a slow postsynaptic current in hippocampal CA3 neurons. Nature 1997,388, 182-6.

[36] Vigne, M.; Collingridge, G.L. The synaptic activation of kainate receptors. Nature 1997,388, 179-82

[37] Lerma, J.; Paternain, A.V.; Rodriguez-Moreno, A.; Lopez-Garcia, J.C. Molecular physiology of kainate receptors. Physiol. Rev. 2001,81, 971-98.

[38] Huettner, J.E. Kainate receptors and synaptic transmission. Prog. Neurobio. 2003,70, 387-407.

[39] Pinheiro, P.; Mulle, C. Kainate receptors. Cell. Tissue Res. 2006,326, 457-82.

[40] Bowie, D. Ionotropic glutamate receptors \& CNS disorders. CNS Neurol. Disord. Drug Targets 2008,7, 129-43.

[41] Lomeli, H.; Sprengel, R.; Laurie, D.J.; Kohr, G.; Herb, A.; Seeburg, P.H.; Wisden, W. The rat delta- 1 and delta-2 subunits extend the excitatory amino acid receptor family. FEBS Lett 1993,315, 318-22.

[42] Palucha, A.; Klak, K.; Branski, P.; van der Putten, H.; Flor, P.J.; Pilc, A. Activation of the mGlu7 receptor elicits antidepressant-like effects in mice. Psychopharmacology (Berl) 2007,194, 555-62.

[43] Heuss, C.; Scanziani, M.; Gahwiler, B.H.; Gerber, U. G-protein-independent signaling mediated by metabotropic glutamate receptors. Nat. Neurosci. 1999,2, 1070-7.

[44] Abe, T.; Sugihara, H.; Nawa, H.; Shigemoto, R.; Mizuno, N.; Nakanishi, S. Molecular characterization of a novel metabotropic glutamate receptor mGluR5 coupled to inositol phosphate/Ca2+ signal transduction. J. Biol. Chem. 1992,267, 13361-8.

[45] Aramori, I.; Nakanishi, S. Signal transduction and pharmacological characteristics of a metabotropic glutamate receptor, mGluR1, in transfected CHO cells. Neuron 1992,8, 757-65.

[46] Ferraguti, F.; Shigemoto, R. Metabotropic glutamate receptors. Cell. Tissue Res. 2006,326, 483-504.

[47] Romano, C.; Sesma, M.A.; McDonald, C.T.; O'Malley, K.; Van den Pol, A.N.; Olney, J.W. Distribution of metabotropic glutamate receptor mGluR5 immunoreactivity in rat brain. J. Comp. Neurol . 1995,355, 455-69.

[48] van den Pol, A.N.; Romano, C.; Ghosh, P. Metabotropic glutamate receptor mGluR5 subcellular distribution and developmental expression in hypothalamus. J. Comp. Neurol.1995,362, 134-50.

[49] Chavis, P.; Shinozaki, H.; Bockaert, J.; Fagni, L. The metabotropic glutamate receptor types $2 / 3$ inhibit L-type calcium channels via a pertussis toxinsensitive G-protein in cultured cerebellar granule cells. J. Neurosci. 1994,14, 7067-76.

[50] Tanabe, Y.; Nomura, A.; Masu, M.; Shigemoto, R.; Mizuno, N.; Nakanishi, S. Signal transduction, pharmacological properties, and expression pattern of two rat metabotropic glutamate receptors, mGluR3 and mGluR4. J. Neurosci. 1993,13, 1372-8.

[51] Tamaru, Y.; Nomura, S.; Mizuno, N.; Shigemoto, R. Distribution of metabotropic glutamate receptor mGluR3 in the mouse CNS: differential location relative to pre- and postsynaptic sites. Neuroscience 2001,106, 481 503.

[52] Kugaya, A.; Sanacora, G. Beyond monoamines: glutamatergic function in mood disorders. CNS Spectr. 2005,10, 808-19. 
[53] O'Shea, R.D. Roles and regulation of glutamate transporters in the central nervous system. Clin. Exp. Pharmacol. Physiol. 2002,29, 1018-23.

[54] Kanai, Y.; Hediger, M.A. The glutamate/neutral amino acid transporter family SLC1: molecular, physiological and pharmacological aspects. Pflugers Arch. 2004,447, 469-79.

[55] Beart, P.M.; O'Shea, R.D. Transporters for L-glutamate: an update on their molecular pharmacology and pathological involvement. Br. J. Pharmacol. 2007,150, 5-17.

[56] Bridges, R.J.; Esslinger, C.S. The excitatory amino acid transporters: pharmacological insights on substrate and inhibitor specificity of the EAAT subtypes. Pharmacol. Ther. 2005,107, 271-85.

[57] Storck, T.; Schulte, S.; Hofmann, K.; Stoffel, W. Structure, expression, and functional analysis of a $\mathrm{Na}(+)$-dependent glutamate/aspartate transporter from rat brain. Proc. Natl. Acad. Sci. U S A 1992,89, 10955-9.

[58] Pines, G.; Danbolt, N.C.; Bjoras, M.; Zhang, Y.; Bendahan, A.; Eide, L.; Koepsell, H.; Storm-Mathisen, J.; Seeberg, E.; Kanner, B.I. Cloning and expression of a rat brain L-glutamate transporter. Nature 1992,360, 464-7.

[59] Kanai, Y.; Hediger, M.A. Primary structure and functional characterization of a high-affinity glutamate transporter. Nature 1992,360, 467-71.

[60] Arriza, J.L.; Fairman, W.A.; Wadiche, J.I.; Murdoch, G.H.; Kavanaugh, M.P.; Amara, S.G. Functional comparisons of three glutamate transporter subtypes cloned from human motor cortex. J. Neurosci. 1994,14, 5559-69.

[61] Arriza, J.L.; Eliasof, S.; Kavanaugh, M.P.; Amara, S.G. Excitatory amino acid transporter 5, a retinal glutamate transporter coupled to a chloride conductance. Proc. Natl. Acad. Sci. U S A 1997,94, 4155-60.

[62] Fairman, W.A.; Vandenberg, R.J.; Arriza, J.L.; Kavanaugh, M.P.; Amara, S.G. An excitatory amino-acid transporter with properties of a ligand-gated chloride channel. Nature 1995,375, 599-603.

[63] Seal, R.P.; Amara, S.G. Excitatory amino acid transporters: a family in flux. Annu. Rev. Pharmacol. Toxicol. 1999,39, 431-56.

[64] Furuta, A.; Martin, L.J.; Lin, C.L.; Dykes-Hoberg, M.; Rothstein, J.D. Cellular and synaptic localization of the neuronal glutamate transporters excitatory amino acid transporter 3 and 4 . Neuroscience 1997,81, 1031-42.

[65] Eliasof, S.; Arriza, J.L.; Leighton, B.H.; Kavanaugh, M.P.; Amara, S.G. Excitatory amino acid transporters of the salamander retina: identification, localization, and function. J. Neurosci . 1998,18, 698-712.

[66] Hamilton, N.B.; Attwell, D. Do astrocytes really exocytose neurotransmitters? Nat. Rev. Neurosci. 2010,11, 227-38.

[67] Parpura, V.; Zorec, R. Gliotransmission: Exocytotic release from astrocytes. Brain. Res. Rev. 2010,3, 83-92.

[68] Axelrod, J. Neurotransmitters. Sci. Am. 1974,230, 59-71.

[69] Boehning, D.; Snyder, S.H. Novel neural modulators. Annu. Rev. Neurosci. 2003,26, 105-31.

[70] Do, K.Q.; Benz, B.; Sorg, O.; Pellerin, L.; Magistretti, P.J. beta-Adrenergic stimulation promotes homocysteic acid release from astrocyte cultures: evidence for a role of astrocytes in the modulation of synaptic transmission. J. Neurochem. 1997,68, 2386-94.

[71] Martin, E.D.; Fernandez, M.; Perea, G.; Pascual, O.; Haydon, P.G.; Araque, A.; Cena, V. Adenosine released by astrocytes contributes to hypoxiainduced modulation of synaptic transmission. Glia 2007,55, 36-45.

[72] Volterra, A.; Meldolesi, J. Astrocytes, from brain glue to communication elements: the revolution continues. Nat. Rev. Neurosci. 2005,6, 626-40.

[73] Pasantes Morales, H.; Schousboe, A. Volume regulation in astrocytes: a role for taurine as an osmoeffector. J. Neurosci. Res. 1988,20, 503-9.

[74] Cotrina, M.L.; Lin, J.H.; Alves-Rodrigues, A.; Liu, S.; Li, J.; Azmi-Ghadimi, H.; Kang, J.; Naus, C.C.; Nedergaard, M. Connexins regulate calcium signaling by controlling ATP release. Proc. Natl. Acad. Sci. U S A 1998,95, $15735-40$

[75] Iglesias, R.; Dahl, G.; Qiu, F.; Spray, D.C.; Scemes, E. Pannexin 1: the molecular substrate of astrocyte "hemichannels". J. Neurosci. 2009,29, 7092-

[76] Szatkowski ,M.; Barbour, B.; Attwell, D. Non-vesicular release of glutamate from glial cells by reversed electrogenic glutamate uptake. Nature 1990,348, 443-6.

[77] Warr, O.; Takahashi, M.; Attwell, D. Modulation of extracellular glutamate concentration in rat brain slices by cystine-glutamate exchange. J. Physiol. 1999,514(Pt 3), 783-93.

[78] Parpura, V.; Basarsky, T.A.; Liu, F.; Jeftinija, K.; Jeftinija, S.; Haydon, P.G. Glutamate-mediated astrocyte-neuron signalling. Nature 1994,369, 744-7.

[79] Hertz, L.; Dringen, R.; Schousboe, A.; Robinson, S.R. Astrocytes: glutamate producers for neurons. J. Neurosci. Res. 1999,57, 417-28.

[80] Westergaard, N.; Drejer, J.; Schousboe, A.; Sonnewald, U. Evaluation of the importance of transamination versus deamination in astrocytic metabolism of [U-13C]glutamate. Glia 1996,17, 160-8.

[81] Araque, A.; Sanzgiri, R.P.; Parpura, V.; Haydon, P.G. Calcium elevation in astrocytes causes an NMDA receptor-dependent increase in the frequency of miniature synaptic currents in cultured hippocampal neurons. J. Neurosci. 1998,18, 6822-9.
[82] Hua, X.; Malarkey, E.B.; Sunjara, V.; Rosenwald, S.E.; Li, W.H.; Parpura, V. C(a2+)-dependent glutamate release involves two classes of endoplasmic reticulum $\mathrm{Ca}(2+)$ stores in astrocytes. J. Neurosci. Res. 2004,76, 86-97.

[83] Montana, V.; Ni, Y.; Sunjara, V.; Hua, X.; Parpura, V. Vesicular glutamate transporter-dependent glutamate release from astrocytes. J. Neurosci. 2004,24, 2633-42.

[84] Zhang, Q.; Pangrsic, T.; Kreft, M.; Krzan, M.; Li, N.; Sul, J.Y.; Halassa, M.; Van Bockstaele, E.; Zorec, R.; Haydon, P.G. Fusion-related release of glutamate from astrocytes. J. Biol. Chem. 2004,279, 12724-33.

[85] Reyes, R.C.; Parpura, V. Mitochondria modulate Ca2+-dependent glutamate release from rat cortical astrocytes. J. Neurosci. 2008,28, 9682-91.

[86] Montana, V.; Malarkey, E.B.; Verderio, C.; Matteoli, M.; Parpura, V. Vesicular transmitter release from astrocytes. Glia 2006,54, 700-15.

[87] Wilhelm, A.; Volknandt, W.; Langer, D.; Nolte, C.; Kettenmann, H.; Zimmermann, H. Localization of SNARE proteins and secretory organelle proteins in astrocytes in vitro and in situ. Neurosci. Res. 2004,48, 249-57.

[88] Anlauf, E.; Derouiche, A. Astrocytic exocytosis vesicles and glutamate: high-resolution immunofluorescence study. Glia 2005,49, 96-106.

[89] Bezzi, P.; Gundersen, V.; Galbete, J.L.; Seifert, G.; Steinhauser, C.; Pilati, E; Volterra, A. Astrocytes contain a vesicular compartment that is competent for regulated exocytosis of glutamate. Nat. Neurosci. 2004,7, 613-20.

[90] Crippa, D.; Schenk, U.; Francolini, M.; Rosa, P.; Verderio, C.; Zonta, M Pozzan, T.; Matteoli, M.; Carmignoto, G. Synaptobrevin2-expressing vesicles in rat astrocytes: insights into molecular characterization, dynamics and exocytosis. J. Physiol. 2006,570, 567-82.

[91] Fremeau, R.T, Jr.; Burman, J.; Qureshi, T.; Tran, C.H.; Proctor, J.; Johnson, J.; Zhang, H.; Sulzer, D.; Copenhagen, D.R.; Storm-Mathisen, J.; Reimer, R.J.; Chaudhry, F.A.; Edwards, R.H. The identification of vesicular glutamate transporter 3 suggests novel modes of signaling by glutamate. Proc. Natl. Acad. Sci. U S A 2002,99, 14488-93.

[92] Maienschein, V.; Marxen, M.; Volknandt, W.; Zimmermann, H. A plethora of presynaptic proteins associated with ATP-storing organelles in cultured astrocytes. Glia 1999,26, 233-44.

[93] Stenovec, M.; Kreft, M.; Grilc, S.; Potokar, M.; Kreft, M.E.; Pangrsic, T. Zorec, R. Ca2+-dependent mobility of vesicles capturing anti-VGLUT1 antibodies. Exp. Cell. Res. 2007,313, 3809-18.

[94] Kang, N.; Xu, J.; Xu, Q.; Nedergaard, M.; Kang, J. Astrocytic glutamate release-induced transient depolarization and epileptiform discharges in hippocampal CA1 pyramidal neurons. J. Neurophysiol. 2005,94, 4121-30.

[95] Xu, J.; Peng, H.; Kang, N.; Zhao, Z.; Lin, J.H.; Stanton, P.K.; Kang, J. Glutamate-induced exocytosis of glutamate from astrocytes. J. Biol. Chem. 2007,282, 24185-97.

[96] Trotter, J.; Karram, K.; Nishiyama, A. NG2 cells: Properties, progeny and origin. Brain. Res. Rev. 2010,63, 72-82.

[97] Bergles, D.E.; Roberts, J.D.; Somogyi, P.; Jahr, C.E. Glutamatergic synapses on oligodendrocyte precursor cells in the hippocampus. Nature 2000,405, 187-91

[98] Butt, A.M.; Kiff, J.; Hubbard, P.; Berry, M. Synantocytes: new functions for novel NG2 expressing glia. J. Neurocytol. 2002,31, 551-65.

[99] Nishiyama, A.; Watanabe, M.; Yang, Z.; Bu, J. Identity, distribution, and development of polydendrocytes: NG2-expressing glial cells. J. Neurocytol. 2002,31, 437-55

[100] Nishiyama, A.; Komitova, M.; Suzuki, R.; Zhu, X. Polydendrocytes (NG2 cells): multifunctional cells with lineage plasticity. Nat. Rev. Neurosci. 2009, 10, 9-22.

[101] Peters, A. A fourth type of neuroglial cell in the adult central nervous system. J. Neurocytol. 2004,33, 345-57.

[102] Bergles, D.E.; Dzubay, J.A.; Jahr, C.E. Glutamate transporter currents in bergmann glial cells follow the time course of extrasynaptic glutamate. Proc. Natl. Acad. Sci. U S A 1997,94, 14821-5.

[103] Clark, B.A.; Barbour, B. Currents evoked in Bergmann glial cells by paralle fibre stimulation in rat cerebellar slices. J. Physiol. 1997,502(Pt 2), 335-50.

[104] Clements, J.D.; Lester, R.A.; Tong, G.; Jahr, C.E.; Westbrook, G.L. The time course of glutamate in the synaptic cleft. Science 1992,258, 1498-501.

[105] Diamond, J.S.; Jahr, C.E. Transporters buffer synaptically released glutamate on a submillisecond time scale. J. Neurosci. 1997,17, 4672-87.

[106] Jabs, R.; Pivneva, T.; Huttmann, K.; Wyczynski, A.; Nolte, C.; Kettenmann, H.; Steinhauser, C. Synaptic transmission onto hippocampal glial cells with hGFAP promoter activity. J. Cell. Sci. 2005,118, 3791-803.

[107] Lin, S.C.; Bergles, D.E. Synaptic signaling between GABAergic interneurons and oligodendrocyte precursor cells in the hippocampus. Nat Neurosci. 2004,7, 24-32.

[108] Lin, S.C.; Huck, J.H.; Roberts, J.D.; Macklin, W.B.; Somogyi, P.; Bergles, D.E. Climbing fiber innervation of NG2-expressing glia in the mammalian cerebellum. Neuron 2005,46, 773-85.

[109] Karadottir, R.; Cavelier, P.; Bergersen, L.H.; Attwell, D. NMDA receptors are expressed in oligodendrocytes and activated in ischaemia. Nature 2005, 438, 1162-6. 
[110] Chittajallu, R.; Aguirre, A.; Gallo, V. NG2-positive cells in the mouse white and grey matter display distinct physiological properties. J. Physiol. 2004,561, 109-22.

[111] Muller, J.; Reyes-Haro, D.; Pivneva, T.; Nolte, C.; Schaette, R.; Lubke, J.; Kettenmann, $\mathrm{H}$. The principal neurons of the medial nucleus of the trapezoid body and NG2(+) glial cells receive coordinated excitatory synaptic input. $J$. Gen. Physiol. 2009,134, 115-27.

[112] Kukley, M.; Capetillo-Zarate, E.; Dietrich, D. Vesicular glutamate release from axons in white matter. Nat. Neurosci. 2007,10, 311-20.

[113] Ziskin, J.L.; Nishiyama, A.; Rubio, M.; Fukaya, M.; Bergles, D.E. Vesicular release of glutamate from unmyelinated axons in white matter. Nat. Neurosci. 2007,10, 321-30.

Received: August 19, 2011

Revised: October 28, 2011

Accepted: October 31, 2011
[114] Paukert, M.; Bergles, D.E. Synaptic communication between neurons and NG2+ cells. Curr. Opin. Neurobiol. 2006,16, 515-21.

[115] Reyners, H.; Gianfelici de Reyners, E.; Maisin, J.R. The beta astrocyte: newly recognized radiosensitive glial cell type in the cerebral cortex. $J$. Neurocytol. 1982,11, 967-83.

[116] Bergles, D.E.; Jabs, R.; Steinhauser, C. Neuron-glia synapses in the brain. Brain. Res. Rev. 2010,63,130-7. 